\title{
El periodismo busca su futuro
}

\author{
Carmen DEL RIEGO* \\ apm@apmadrid.es
}

(Abstracts y palabras clave al final del artículo)

Enviado: 25 de marzo de 2013

Evaluado: 30 de marzo de 2013

Aceptado: 1 de abril de 2013

Con un paro registrado en septiembre de 2012 de 27.443 periodistas, el triple que un año antes, de un total estimado de licenciados en periodismo en toda España de 74.923 en esa misma fecha queda claro que la profesión periodística está atravesando por uno de sus peores momentos, al menos en el aspecto laboral y en lo relativo a la precariedad profesional. Una situación de las condiciones de trabajo deteriorada, es verdad que como en otros muchos sectores, que va en detrimento de la calidad del producto que se ofrece a los ciudadanos, que no sería tan importante si lo que elaboran los periodistas no fuera la garantía de un derecho constitucional que tienen los españoles, el derecho a la información, reconocido en el artículo 20 de la Constitución.

Es esta condición de soporte de un derecho constitucional, como ocurre con los médicos o con los maestros, la crisis trasciende la situación del periodismo y hace que los problemas que vive esta profesión, que como dijo Gabriel García Márquez es "el mejor oficio del mundo" incumba no sólo a los profesionales que se dedican a la noble tarea de informar, sino a todos los ciudadanos, como ocurre, estamos viendo, con la Sanidad y la Educación.

Sin embargo, las calles de todas las ciudades de España se han llenado de Mareas Verdes, que luchan por una educación pública y de calidad, y Mareas Blancas, que han adoptado el lema: "la Sanidad se defiende, no se vende", pero a nadie se le ha ocurrido convocar jornadas de lucha y actos de resistencia para defender un periodismo veraz y de calidad, para reivindicar el cumplimiento de ese artículo 20.1.d de la Constitución, del que los periodistas muchas veces nos hemos apropiado, cuando el verdadero destinatario es el ciudadano: Se reconocen y protegen los derechos "a comunicar o recibir libremente información veraz por cualquier medio de difusión..."

\footnotetext{
* Presidenta de la Asociacion de la Prensa de Madrid.
} 
La razón de que las Mareas sociales que han llevado a la conciencia ciudadana los derechos que tienen reconocidos y garantizados no incluya el derecho a la información, que no ocupa cualquier lugar, sino uno destacado en la sección $1^{\mathrm{a}}$ del Capítulo dedicado a Derechos y Libertades de la Constitución española de 1978, la dedicada a los derechos fundamentales y las libertades públicas, pueden ser muchas. Podrían apuntarse dos: que el derecho a la información, sobre todo en los últimos tiempos, no lo garantizan los poderes públicos, no lo garantizan unos medios públicos, la Radio y la Televisión Pública, que en apenas un año han perdido más de 500.000 oyentes Radio Nacional de España, y el 20\% de sus espectadores los informativos de La 1 de Televisión Española; sino que está en manos privadas, que con sus condicionamientos ideológicos y económicos siguen fieles a las citas con sus espectadores, oyentes o lectores, incluso cuando las cifras económicas parece que les aboca al cierre. $\mathrm{Y}$ en segundo lugar porque pese a todo, y aunque muchas veces nosotros mismos, los periodistas, reneguemos de nuestra profesión, en España se sigue haciendo periodismo, y nuestra profesión sigue cumpliendo con el fin social para el que nació, ese fin de servicio público que tiene como principal objetivo el control del poder y los poderosos, y la explicación a los ciudadanos de lo que hacen quienes toman las decisiones, a la vez que transmitimos a quienes están en los puestos de poder y van a determinar la vida colectiva en función de la decisión que adopten, la opinión de la sociedad sobre lo que hacen y sobre lo que quieren que hagan.

Es difícil hacer estas afirmaciones cuando el barómetro del CIS (Centro de Investigaciones Sociológicas), de febrero de 2013, coloca a los periodistas como la segunda profesión peor valorada entre 16, aunque apruebe con un 5,9, una nota sólo superada por abajo, en apenas 9 centésimas, por la opinión que tienen los ciudadanos de los jueces. Hasta los albañiles, fontaneros y barrenderos son profesiones mejor valoradas que la periodística. Los médicos y los maestros o profesores de educación infantil, primaria, secundaria y universidad son los mejor valorados, con un 8,1 los médicos y con un 7,4 los profesores.

Se puede buscar una explicación en que mientras la educación y la salud son servicios básicos que priman sobre cualquier otra cosa a la hora de valorar la calidad de vida de los ciudadanos, el periodismo no se considera vital para poder lograr un desarrollo pleno de la persona. La gente puede vivir sin periódicos. En nuestro deber, el de los periodistas, y en el de la sociedad en general, está el no haber sabido llevar a la conciencia ciudadana que se puede vivir sin periódicos, pero no se puede vivir sin información, porque cuando una sociedad no está informada, o la información que recibe no es plural, no es veraz, o no es libre, los ciudadanos tampoco lo son y corren muchos más riesgos de caer en las garras de unos poderes políticos que vayan contra ellos mismos y sus intereses, porque la elección que ellos hagan de esos representantes políticos no contarán con el suficiente conocimiento y discernimiento sobre lo que ofrecen sus programas políticos, o lo que pueden hacer esos políticos con su voto.

La información es poder, es la adaptación popular de la frase atribuida al filósofo, economista e historiador escocés del siglo XVIII David Hume, que dijo que " $E l$ conocimiento es poder", y 300 años después sigue siendo verdad y la base del hombre libre. Primero necesita tener acceso a la información, al conocimiento, y si el 
acceso a la educación supuso un paso fundamental para lograr que los súbditos dejaran de serlo y se convirtieran en ciudadanos, una vez que tienen acceso al conocimiento, también requieren contar con la información necesaria para entender la sociedad en la que viven y poder ser dueños de su destino. Una visión un tanto romántica del periodismo, que resumió perfectamente en una frase el dramaturgo estadounidense Arthur Miller: "Un buen periódico es una nación hablándose a si misma".

Por eso duele tanto una valoración de la profesión periodística como la que refleja el CIS de febrero de 2013, en un momento en el que el periodismo creíamos que estaba volviendo a cumplir esa tarea de servicio público que lo justifica, con la denuncia de los casos de corrupción que se dan en el poder, cuando uno de los pecados en los que el periodismo había podido incurrir en otros momentos y que había contribuido a nuestro desprestigio, fue la connivencia con el poder. Un vistazo a los periódicos de los últimos meses podría haber llevado al ánimo ciudadano que se había abandonado esa mala práctica, aunque quizá lo que ocurra es que estemos cumpliendo nuestra penitencia. De igual forma la llevarán los jueces, que junto con los periodistas son, o creíamos que eran, en quienes los ciudadanos tenían puestas sus esperanzas para limpiar la sociedad, una vez que hemos puesto encima de la mesa, unos y otros, las conductas irregulares de las personas que hasta entonces tenían la confianza social.

Ese barómetro del Centro de Investigaciones Sociológicas indica que el principal problema que los ciudadanos creen que tiene España es el paro, y el segundo la corrupción, el tercero la situación económica y el cuarto la política y los políticos. El gran problema que podemos tener que afrontar desde la profesión, es si dentro de ese apartado de política y políticos nos incluyen a los periodistas, porque nos hayan visto como parte de un todo, instalados en los aledaños del poder, y de espaldas a ellos. La corrupción irrumpió como problema hace tan sólo unos meses, después de que los medios de comunicación empezaran a informar profusamente y los jueces a investigar y hallar pruebas de que se habían producido en las más altas esferas del poder las conductas denunciadas, lo que puede llevarnos a pensar, y posiblemente no nos equivoquemos, que los ciudadanos no han tomado conciencia de que existía el problema hasta que los medios de comunicación no lo hemos abordado, aunque existiera mucho antes, como ha podido pasar en otros muchos aspectos de la vida diaria de los ciudadanos.

Estos problemas, han tenido que atenazar a los poderes públicos, impedirles ejercer su labor y han tenido que airear sus vergüenzas para que los ciudadanos admitan que existen. No es sólo el caso Bárcenas, que afecta al PP, o el caso Campeón que puede afectar al PSOE, es sobre todo el caso Urdangarín, con el que los ciudadanos han dicho Basta. Es el que ha puesto en jaque a una Monarquía que hasta hace muy poco tiempo gozaba del prestigio y del reconocimiento de la mayoría de los ciudadanos, y que una caída inoportuna en una cacería fuera de lugar, en compañías no muy recomendables del Rey Don Juan Carlos, han tirado por los suelos los afectos y la reputación ganada a pulso por La Casa Real. Si el desgaste es recuperable se verá, pero los periodistas, y los jueces, han cumplido con su deber. 
Quizá antes no lo hicimos, cuando se sospechaba pero no se expresaba, y ahora estemos pagando la factura de aquello.

En estos casos, como en la lucha por los servicios públicos propios del Estado del Bienestar, ha tenido y tiene un papel muy importante, vital, para que los ciudadanos tomen conciencia de lo que está ocurriendo, de lo que se juegan, ellos y la sociedad, y de que en sus manos está cambiar el futuro que les quieren imponer, el periodismo. Los ciudadanos han salido a calle y los medios de comunicación les han secundado. No sé quiénes han sido los primeros en levantar la voz si los periodistas o los ciudadanos, o quizá unos son consecuencia de los otros, o los dos a la vez, porque al fin y al cabo el periodismo es la traducción pública del sentir ciudadano, pero lo hemos hecho juntos, aunque los ciudadanos no lo hayan percibido todavía. Periodismo en estado puro.

Tampoco hay que hacer un drama de esos datos que nos han sacudido a todos, porque lo sabíamos. Son datos muy similares a los que recoge el Informe Anual de la Profesión Periodística de 2012, editado por la Asociación de la Prensa de Madrid (APM), con un añadido, los periodistas somos más críticos y más exigentes con nosotros mismos que los ciudadanos. No se trata, en el informe, de poner una nota a los periodistas, a la profesión, pero sí de juzgar uno de los principios fundamentales que sin duda tiene en cuenta la sociedad cuando juzga nuestra labor: la independencia, y en ese aspecto nosotros mismos nos suspendemos, nos damos un 4,09, mientras que los ciudadanos son generosos y nos aprueban, aunque sea con un 5 raspado $(5,42)$. Ese es el grado de confianza que le merece la información elaborado por los periodistas, prácticamente la misma nota que el CIS da a nuestra profesión. La autocrítica que somos capaces de hacer desde dentro de la profesión, es un buen principio para la recuperación de los valores de nuestra profesión.

Porque el periodismo, por muchos siglos que pasen, aunque remontemos su existencia, que sería discutible, al "acta Diurna" que Julio César colocó en el Foro Romano en el Siglo Primero antes de Cristo, o ya con más motivos lo situemos en La Edad Media, en las hojas escritas con noticias económicas y comerciales que se vendían en Venecia al precio de una gaceta, la moneda veneciana del siglo XVI que dio nombre a muchos periódicos modernos, o lo fechemos posteriormente con el desarrollo de la imprenta y la revolución industrial, el periodismo sigue siendo lo mismo, "la recopilación y análisis, ya sea de modo escrito, oral, visual o gráfico de la información, en cualquiera de sus formas, presentaciones y variedades", por elegir una descripción de tantas, que formulan con palabras distintas la esencia de esta profesión. Una definición que sirve incluso para lo que algunos llaman el nuevo periodismo, el periodismo digital, el periodismo 2.0, que no es más que lo mismo que era antes el periodismo, pero utilizando otras herramientas y aprovechando la revolución industrial del siglo XXI, las Nuevas Tecnologías.

Un periodismo que está en crisis porque el vehículo en el que caminaba se ha quedado obsoleto y todavía no ha encontrado el que sea capaz de circular por las rapidísimas autovías que hoy utilizan los ciudadanos. Mientras, camina errante sin saber cuál será su casa definitiva, intentando seguir cumpliendo con su papel, en una sociedad cada vez más compleja, que por ello exige cada vez a los periodista y necesita más de ellos. Una sociedad, la sociedad de la información se la ha llamado, que 
acumula tal cantidad de datos a disposición de los ciudadanos, y de una forma tan fácil y barata de conseguir, que hace que los ciudadanos tengan problemas para digerirla, (la información y los datos), y aunque no lo sepan, vayan a tener que recurrir a los periodistas, al periodismo, en el formato que sea, para poder de nuevo saber con certeza cuál es la verdad y qué es lo que está sucediendo a su alrededor. Una exigencia que tarde o temprano llegará, cuando los ciudadanos se den cuenta de que mucha información que llega a sus manos envuelta en datos atractivos o en escándalo atrayente, obedecen a intereses muchas veces inconfesables, que tienen un origen muy distinto al que aparentan y que si conocieran de verdad quiénes están detrás de ella, la rechazarían de plano, pero la reciben con un objetivo que muchas veces no pueden alcanzar ni siquiera a imaginar.

Uno de los maestros del periodismo, Ryszard Kapuscinski, puso en su justo término lo que suponen las nuevas tecnologías en nuestra profesión, con la conclusión de que ellas no podrán sustituirnos, por mucho que algunos lo intenten: "Nuestra profesión necesita nuevas fuerzas, nuevos puntos de vista, nuevas imaginaciones, porque en los últimos tiempos ha cambiado de una forma espectacular. Las nuevas tecnologías facilitan nuestro trabajo, pero no ocupan su lugar".

Un mensaje que debe llegar a quienes quieren sustituirnos por una información directa, con la única intención de que lo que es propaganda parezca información, para que sea más creíble, pero también a los periodistas, que se acomodan a hacer periodismo sentados a una mesa viendo una televisión, porque es más barato y más cómodo, y a los editores o pseudo editores que quieren tener un medio de comunicación para tener poder, pero no para que la información llegue a los ciudadanos, son lo que Michael Ignatieff llama "conglomerados mediáticos que no están invirtiendo lo suficiente para cubrir las historias sobre el terreno" y se pregunta "¿tienen los dueños los bolsillos preparados para el gran periodismo?".

La respuesta es no, por muchas razones, pero por una que deberíamos denunciar desde el mismo periodismo, por los medios parásitos que viven de los otros medios desde que se inventó Internet y por alguna razón, que algún día alguien investigará, se decidió que todo lo que fuera información tenía que ser gratis, en abierto, tenía que estar a disposición de cualquiera sin que nadie sufragara los enormes gastos que le suponen a un editor hacer buen periodismo, a quien tiene el coraje de invertir dinero en medios, en formación y en periodistas, para que estos cumplan con su papel, para que estén en los sitios, para que lleguen hasta lugares a los que es difícil acceder, para pagar el sueldo a profesionales que pueden estar semanas investigando un asunto porque hay detrás un editor que ha apostado por la información y por el periodismo, el que sólo merecería llevar ese nombre, y se encuentra con que nada más estar en la red, medios que dicen hacer periodismo y que lo único que hacen es copiar y robar el trabajo de los demás, lo publican sin ningún pudor, como si ellos también hubieran estado allí, sin cambiar apenas una coma, hacen que muchos editores y muchos periodistas se planteen si merece la pena gastarse tanto dinero para que el trabajo y el es fuerzo económico, humano y profesional que se ha hecho, se convierta en apenas unos minutos en trabajo de todos.

Estas reflexiones no son una crítica de quien trabaja en un periódico en papel, con más de 30 años de ejercicio de la profesión a sus espaldas, ni es un rechazo a las 
nuevas tecnologías y los cambios que sufren la profesión. En absoluto. Internet ha cambiado la sociedad de tal forma y ofrece unas posibilidades tan profundas que le hacen digna ser considerada una nueva revolución industrial. Al globalizar el mundo, acerca a cada rincón de la tierra las oportunidades necesarias para hacerla más igual. Yo me apunté enseguida a esta revolución. De lo que estoy en contra es del mal uso de las nuevas tecnologías, y en el periodismo, como en otros sectores, hay personas que hacen mal uso de la herramienta, provocando grandes perjuicios a los demás.

Coincido por ello, bastante, con las conclusiones que saca el Informe Anual de la Profesión Periodística 2012, de la APM, que subrayan que para los periodistas, no todo es positivo en la expansión de internet en el ámbito de la comunicación. Ningún periodista alberga dudas sobre el carácter de medios de comunicación de los llamados medios digitales, pero no todo lo que está en Internet es periodismo, y en eso, también afortunadamente, los periodistas estamos bastante de acuerdo. Sólo el $34,9 \%$ de los profesionales encuestados para el Anuario creen que los blogs son medios de comunicación social, entendidos como el vehículo que tiene el ciudadano para acceder a la información; sólo el 17 por ciento otorga ese calificativo a los portales y baja hasta el 16 los que consideran que las plataformas de microblogging como Twitter son medios periodísticos. Sin embargo existe un acuerdo importante al considerar que Internet fortalecerá a la profesión periodística. Lo cree así el 62,5\% de los encuestados, lo que no impide criticar lo que es criticable en Internet, porque lo es también en cualquier otro soporte periodístico: dar crédito al rumor, la poca exigencia de calidad en la información que se proporciona, primar la rapidez sobre la confirmación y la veracidad y no diferenciar el trabajo de los profesionales del periodismo de las personas que proporcionan informaciones que deberían ser sometidas a un proceso de contraste propio del periodismo, y que sin embargo se revisten, para no llevar a cabo ese trabajo del mal llamado "periodismo ciudadano".

Por todo eso es más grave que el periodismo, cuando es más necesario que nunca para que los ciudadanos puedan discernir la información que reciben, esté inmerso en la explicada doble crisis que nos atenaza, no desde que empezó la crisis económica, en 2007, sino una década antes, cuando en los 90, las nuevas tecnologías empezaron a poner en manos de los ciudadanos la información de forma gratuita y llegaba mucho más rápida de lo que estaban acostumbrados a recibirla, incluso mediante la radio y la televisión. Es la crisis que ha provocado en el periodismo las nuevas tecnologías, a la que después se ha sumado la crisis económica que el sector periodístico ha vivido y vive como cualquier otro, y que ha sido largamente analizado en el libro del catedrático Bernardo Díaz Nosty y editado en 2012 por la APM "El libro negro del periodismo en España". Una crisis que no ha hecho más que profundizarse a finales de 2012 y en lo que va de 2013, pese a los proyectos nuevos de comunicación que se están poniendo en marcha, con nuevas fórmulas empresariales, entre los que podríamos citar Zoomnews, eldiario.es o Infolibre, todos ellos en formato digital, que son encomiables, aunque tengan como referencia el papel y no varíen mucho del periodismo que se hace en los periódicos que todavía necesitan una rotativa para estar en la calle. Se están convirtiendo en referentes del periodismo en Internet, como lo son Elconfidencial.com, Vozpopuli o Libertad digital, que 
no se diferencian gran cosa, salvo el soporte, del periodismo que se hace en los medios tradicionales. A todos ellos hay que desearles suerte.

En su mayoría, curiosamente, son proyectos empresariales que están llevando a cabo editores que hasta ahora sólo eran periodistas, haciendo que lo que tradicionalmente han sido dos profesiones muy diferenciadas, aunque vivían la una al lado de la otra, se hayan fundido en una sola, sin que podamos saber todavía si eso es bueno, o si los intereses que deben defender unos editores son compatibles con los que deben poner en práctica los periodistas.

Son proyectos que apenas suponen una gota de respiro en la mala situación del oficio que reflejó una vez más el Informe de la Profesión Periodística 2012 de la Asociación de la Prensa de Madrid. Un informe que describe una penosa situación de la industria de medios, en la que la facturación agregada en diarios, televisiones, radios y revistas de quioscos se redujo un 7\%, hasta los 6.588 millones de euros en 20011, y en los que las televisiones y los diarios representaron el $85 \%$ de la caída de los ingresos del sector. Un descenso que se acumula al de años anteriores y que hace que entre 2007 y 2011 la factura agregada de todos los medios se redujera un 26\%, pasando de los 8.886 millones de euros a los 6.558 actuales. Todos los apartados que soportan la industria está en números rojos: La inversión publicitaria total, que es lo que ha mantenido a los medios de comunicación, ha caído un $38 \%$ en el periodo 2007-2011 y la publicidad institucional se ha rebajado en un 63\%. En esos cinco años se ha dejado de vender en los quioscos casi uno de cada cuatro ejemplares de diarios de pago (el $23 \%$ de disminución) y la circulación de la prensa gratuita se ha reducido a la tercera parte $(-66 \%)$. Poniendo nombres a estos fríos datos, los ingresos de los grupos de comunicación en España han descendido de forma importante en este periodo: Prisa, -26\%; Antena 3, -21\%; Telecinco-Mediaset, -7\%, Vocento, $25 \%$; Unedisa, -20\%; Grupo Godó, $-28 \%$ y Zeta $-37 \%$.

Podría parecer que el periodismo no tiene por qué preocuparse por los ingresos de los medios de comunicación, pero nos engañaríamos si lo hiciéramos. Sin esos grupos editoriales fuertes que inviertan en el producto no se puede hacer periodismo, y los ciudadanos no tendrán acceso a la información que necesitan para entender el mundo que les rodea. Que entre 2008 y noviembre de 2012 hayan cerrado 179 medios de comunicación: 22 diarios, 132 revistas, 20 televisiones de todos los ámbitos, cuatro radios, 10 periódicos gratuitos, 7 medios digitales y dos agencias, no es sólo un problema de los periodistas, es un problema social., también de los ciudadanos que ven que su derecho a una información plural se resiente.

Un panorama negro que sufrimos los periodistas, pero también, aunque no lo perciban de la forma dramática con la que nosotros lo afrontamos, los ciudadanos que ven resentido su derecho a una información plural, aunque preocupados en cubrir otras necesidades básicas no lo asuman así. A los ciudadanos les pueden dejar fríos las cifras de paro que se desprende de esta crisis, que no empezó con la crisis económica sino que tuvo su primer punto de inflexión con el ERE que llevó a cabo RTVE en 2006, que afectó a 4.150 empleados mayores de 50 años, a los que se prejubiló en unas condiciones que ahora, con las sucesivas reformas laborales, parecen muy beneficiosas. Fue sólo el inicio. La destrucción de empleo consumada desde 2008, cuando la crisis económica dio la cara, hasta finales de 2012, alcanzó los 6.393 
puestos de trabajo, en los medios de comunicación, no sólo periodistas, y estaban en ese momento en negociación ERES que suponían la pérdida de otros 2.990 empleos, con lo que podría decirse que se acercan a los 10.000 los puestos de trabajo perdidos en los medios de comunicación desde el inicio de la crisis, la mayor parte, en contra de lo que pueda parecer, en televisiones, seguidos por los empleos que se han reducido en periódicos diarios de pago, revistas, y periódicos gratuitos. En total, según datos del Servicio Público de Empleo Estatal (SEPE), en septiembre de 2012 había 13.383 personas que demandaban empleo como periodistas, en primera opción, frente a los 11.079 del mismo mes del año anterior, y había 10.549 parados registrados como periodistas, frente a los 8.520 de un año antes. En ambos casos, el paro entre los periodistas ha sido superior al $20 \%$ en un año.

Pueden parecer pocos si se comparan con las cifras absolutas de personas afectadas por Expedientes de Regulación de Empleo en otros sectores, que hablan de 30.000 afectados en la banca, 40.000 en la industria automovilística, 200.000 empleos públicos perdidos en un año, pero no por ello resultan menos dramática. El público, los ciudadanos nos han abandonado, por motivos económicos, seguro, porque encuentran en Internet, de forma gratuita, una forma de informarse que les resulta cómoda, sencilla y sobre todo barata, pero también, y debemos reconocerlo si no queremos engañarnos a nosotros mismos, lo que no nos ayudará a encontrar el camino del futuro de esta profesión que nunca desaparecerá mientras exista una sociedad, es que no hemos sabido dar a los ciudadanos la información que requieren.

No es que tengamos que hacer caso de las audiencias, como ocurre en muchos programas de televisión, de ocio o de espectáculo, en los que muchas veces se reviste de periodismo lo que sólo es eso, espectáculo, pero tenemos que repensar la información que los medios de comunicación proporcionamos, aunque sólo sea por nuestra supervivencia, y adaptarla a lo que los ciudadanos necesitan saber para ser eso, ciudadanos libres. Los datos demuestran que los ciudadanos compran información cuando se les da información relevante y de calidad, si no, se conforman con las tres primeras líneas de una información que pueden leer gratis en Internet.

$\mathrm{Al}$ afrontar ese reto, el del periodismo en busca de su futuro, sólo se me ocurre volver a los valores del periodismo al más puro estilo clásico, aunque se materialice en el formato digital más desarrollado, en el menor número de caracteres posible, lo que sigo empeñada, y lo estaré hasta que no me demuestren lo contrario, en considerar imposible. Nadie es capaz de hacer periodismo en 140 caracteres, porque la realidad está llena de matices, y aunque el modelo de negocio esté más perdido que los propios periodistas, y todavía no hayamos sido capaz de llevar a la conciencia ciudadana el convencimiento de que hacer periodismo cuesta dinero, y que si la publicidad no cubre esos ingresos, que no los cubre, aunque hasta ahora haya sido la base del negocio en los medios tradicionales, escritos, de radio o televisión, tienen que encontrar el negocio en otro sitio.

Mientras ese nuevo modelo llega, que llegará, aunque no sabemos cuándo ni cuantos medios y periodistas se quedarán o nos quedaremos por el camino, sólo podemos seguir apostando por el periodismo, por el que tiene la verdad como primer principio, de acuerdo con el ensayo que sobre periodismo han publicado Bill Kovach y Tom Rosentiel bajo el título Los elementos del periodismo, todo lo que los 
periodistas deben saber y los ciudadanos esperar, editado por Aguilar en 2012. Verdad, lealtad, verificación, independencia, foro público, información significante sugerente y relevante, exhaustividad, respeto a la conciencia individual y control independiente del poder. Todo eso constituye, según Kovach y Rosentiel, la esencia del periodismo que hará que los ciudadanos que en el último barómetro del CIS han demostrado tener una imagen tan pobre de la profesión periodística, se decidan a reivindicar, sino es en las calles en forma de Marea, al menos en voz alta, una información de calidad que les permita ser capaces de formar sus propias conciencias, de tener la información y el conocimiento que les haga libre, y así elegir mejor la sociedad en la que quieren vivir y los políticos que quieren que las dirijan.

Es un trabajo que no pueden, que no podemos hacer sólo los periodistas, deben hacerlo también los ciudadanos, y los editores que se convencerán de que si hacen el producto con esos ingredientes, lo venderán, porque responderá a las demandas de los ciudadanos. El que se elabore teniendo en cuenta esos principios será rentable, será el medio de comunicación que elijan los ciudadanos para informarse, porque en él reconocerán no sólo una ideología, la más cercana a la suya, a su forma de entender la sociedad, o que mejor refleje la sociedad a la que pertenece desde su mismo punto de vista, lo que no es malo si no deja de ser ideología para ser militancia incondicional, sino también porque en ese medio encontrarán otros valores del periodismo: honradez, prestigio y criterio, el de los periodistas que trabajan para trasladarles esa visión de la realidad, esa verdad, que puede no ser una verdad absoluta, pero que es producto del compromiso que tienen los periodistas con los ciudadanos, porque el periodismo, a pesar de todos los cambios que ha experimentado y experimenta la propia sociedad, tiene un objetivo que permanece inalterable y que hemos repetido a lo largo de este artículo: proporcionar a los ciudadanos la información que necesita para ser libre y poder elegir su modo de vida o de gobierno.

No todo es negro. Los periodistas y los ciudadanos tenemos razones para la esperanza. En el citado Informe Anual de la Profesión Periodística 2012, junto a todos los malos datos sobre empleo hay un capítulo sobre ética muy reseñable y que nos permite atisbar un futuro, no voy a ponerle calificativo, pero un futuro. Los periodistas rechazamos determinados métodos de conseguir la información. Consideramos que existen ciertos límites de procedimiento a la hora de buscar la información. Limites que tienen que ver con la privacidad de quienes protagonizan las informaciones, con la fidelidad debida a fuentes y a los destinatarios de la información o con las herramientas empleadas para conseguir y mostrar información. El $98 \%$ de los periodistas están en contra de romper una promesa de confidencialidad hecha a una fuente, y el 90,3\% está en desacuerdo con informar sobre asuntos en los que se tiene un interés personal sin advertírselo al receptor. Es decir, afortunadamente, y pese a todos, los periodistas seguimos siendo un colectivo con ética, con convicciones cercanas a las ideas clásicas del periodismo y bastante alejado del relativismo.

Esa conciencia es la que nos debe permitir hacer un periodismo que tenga como referente a quien va dirigido, al ciudadano, no a las fuentes, ni al poder sea político o económico, sino que piense sólo y únicamente en los ciudadanos, en sus aspiraciones, en sus necesidades, en lo que tienen el derecho a saber, a conocer. Para ello, 
lo primero que no tienen que olvidar nunca los periodistas es que son también ciudadanos, que tienen los mismos intereses, que no son, en la mayoría de los casos, los de esos poderes o intereses ante los que el periodismo ha claudicado tantas veces, $\mathrm{ni}$ son siquiera el de los editores, que sin embargo verán los resultados del negocio si los periodistas conectan con lo que los ciudadanos necesitan y por lo tanto van a demandar.

Un periodismo que no se acomode a lo fácil y se quede con lo primero que alguien cuenta, sin que se sepa el origen y sobre todo, no se compruebe que es verdad. Es difícil confirmar una información. La realidad puede estropearnos un buen titular, pero los ciudadanos no son tontos, y además ahora tienen a su alcance muchas formas de obtener información, de contrastarla, aunque no dispongan de tiempo para hacerlo, y si nos cogen en un renuncio, en un engaño, morirá. Para otros queda el entretenimiento de hablar sobre ficción, sobre rumores o de convertirse en simples comentaristas de lo que parece que es, en vez de profundizar en la realidad, que es al fin y al cabo lo que es el periodismo: Ir más allá, saber la realidad y encontrarle una explicación, contextualizar un dato para que tenga sentido, para que así sea capaz de responder a las preguntas que se hacen los ciudadanos sobre todas las cosas que les rodean.

Un periodismo que vuelva a las raíces, en el que el periodista sea siempre periodista y por lo tanto no se convierta nunca en protagonista de la historia. Hay que abominar de quienes creen que la verdad pasa por ellos y que son más importantes que los propios protagonistas de la historia que los ciudadanos deben saber. Un periodismo en el que la noticia, el dato, la verdad prime sobre palabras vacías, imágenes irrelevantes o historias fabricadas. Un periodismo donde los testimonios que se incorporen a la historia sean porque aporten algo, porque hayan sido de verdad testigos de lo que se cuenta y ayuden a conformar una historia con muchos pequeños testimonios que compongan un todo, y no se quede con el primero que pasa por allí, porque lo importante es contar algo, lo que sea, antes que nadie.

Un periodismo que elija las historias y los hechos más relevantes, y no las más fáciles o los que interesan a sectores muy determinados, bien porque proporcionen dinero, o porque sean más cómodos con el poder. Un periodismo, en fin, que vuelva a la esencia del periodismo. Un periodismo a la antigua usanza, el que se hacía antes de que los medios de comunicación cayeran en manos de intereses económicos ajenos al periodismo. Un periodismo riguroso, analítico, veraz e independiente. El periodismo de siempre que ha sustituido la linotipia por las herramientas digitales, un periodismo en el que el soporte sea lo único diferente.

Un periodismo que devuelva la confianza de los ciudadanos en los periodistas. Y por si sirve de guía, hacer mías las palabras del periodista canadiense Michael Ignatieff, en su discurso de aceptación del XXIX Premio de Periodismo Francisco Cerecedo que concede la Asociación de Periodistas Europeos: "Confio en los periodistas que piensan que los hechos son tozudos, en quienes cambian de opinión cuando cambian los hechos, en los periodistas que escuchan más que hablan, en aquellos cuy a autoridad viene de haber estado ahi . Confio en el periodista que se toma la molestia de hablar con unas hermanas que pueden perder su casa en Madrid por un desahucio, que me cuenta lo que las hermanas ganan cada mes, cuáles son las 
reglas del banco y que me explica exactamente por qué estas hermanas lucharán hasta la extenuación por no acabar en la calle".

\title{
RESUMEN
}

Reflexión a partir de datos muy actualizados sobre el presente crítico del periodismo en España. La autora analiza las causas, circunstancias y previsiones que existen en el periodismo de nuestro país, abogando por la permanencia de la profesión a partir de la conservación de la calidad en el trabajo y los valores morales más profundos como sus motivaciónes.

Palabras clave: crisis periodística, España, calidad, periodismo, empresa informativa.

\begin{abstract}
This article reflects upon the most recent data of the critical situación of professional journalism in Spain. The autor analises the causes, circumstances and the future perspectives of the job in our country, defending the survival of the profession, if the quality at work and the moral roots of the journalism are well settled and diffused in the profesional context.
\end{abstract}

Keywords: crisis in journalism, Spain, quality, news business, future.

\section{RÉSUMÉ}

Cet article réfléchit sur les plus récentes données autour de la critique situation professionnelle du journalisme en Espagne. L'auteur analyse les causes, circonstances et les prévisions pour cet exercice professional, et montre ses meilleurs vœux sur ce future à condition de que la qualité dans le métier et les racines morales dans les motivations professionnelles se récupèrent et soignent dans la profession journalistique.

Mots clé: crise dans le journalisme, Espagne, qualité, entreprises de l'information. future. 